\title{
Drivers and sources of supply flexibility: An exploratory study
}

\author{
Elcio Mendonça Tachizawa ${ }^{1 \mathrm{~T}}$ * \\ Universitat Pompeu Fabra \\ Cristina Giménez ${ }^{2 \mathrm{~T}}$ \\ ESADE Business School - Universitat Ramon Llull
}

September 2005

\footnotetext{
${ }_{1 *}$ Department of Economics and Business; Universitat Pompeu Fabra; Ramon Trias Fargas, 25-27, 08005 Barcelona, Spain; elcio.mendonca@upf.edu, tel. +34 93542 1621. Corresponding author.

${ }^{2}$ Department of Operations and Innovation Management; ESADE Business School - Universitat Ramon Llull; Av. de Pedralbes, 60-62, 08034 Barcelona, Spain; cristina.gimenez@esade.edu, tel. +34 932806162.

${ }^{\mathrm{T}}$ The authors acknowledge financial support from research grant SEC2003-01991/ECO.
} 


\begin{abstract}
Purpose - There has been much research on manufacturing flexibility, but supply chain flexibility is still an under-investigated area. This paper focuses on supply flexibility, the aspects of flexibility related to the upstream supply chain. Our purpose is to investigate why and how firms increase supply flexibility.

Methodology/Approach - An exploratory multiple case study was conducted. We analyzed seven Spanish manufacturers from different sectors (automotive, apparel, electronics and electrical equipment).

Findings - The results show that there are some major reasons why firms need supply flexibility (manufacturing schedule fluctuations, JIT purchasing, manufacturing slack capacity, low level of parts commonality, demand volatility, demand seasonality and forecast accuracy), and that companies increase this type of flexibility by implementing two main strategies: "to increase suppliers' responsiveness capability" and "flexible sourcing". The results also suggest that the supply flexibility strategy selected depends on two factors: the supplier searching and switching costs and the type of uncertainty (mix, volume or delivery).
\end{abstract}

Research limitations - This paper has some limitations common to all case studies, such as the subjectivity of the analysis, and the questionable generalizability of results (since the sample of firms is not statistically significant).

Implications - Our study contributes to the existing literature by empirically investigating which are the main reasons for companies needing to increase supply flexibility, how they increase this flexibility, and suggesting some factors that could influence the selection of a particular supply flexibility strategy.

JEL codes: M11, L60, L24

Keywords: supply flexibility, sourcing, Spain, case study 


\section{Introduction}

Nowadays, many companies are facing a highly volatile and uncertain environment: short product life cycles, frequent and unpredictable changes in demand (in volume and mix), and global logistics issues. This has led companies to put more pressure on their ability to change or react to environmental uncertainty with little penalty in their performance. In other words, companies have become more aware of the need to be flexible.

In the last decade, there has been a considerable amount of research on manufacturing flexibility (e.g. Koste and Malhotra, 1999; Vokurka and O’Leary-Kelly, 2000; Jack and Raturi, 2002; Koste et al., 2004) and an increasing tendency to extend this approach to other processes within the supply chain, i.e. supply, delivery and product development (Duclos et al., 2003; Pujawan, 2004). This extension to consider the supply chain is justified by the acknowledgement by both practitioners and academics that complex supply chains are progressively connecting firms and that the focus on internal (i.e. manufacturing) flexibility might be insufficient to deal with an increasingly turbulent environment (Prater et al., 2001; Jack and Raturi, 2002; Narasimhan and Das, 2000).

This paper contributes to this debate by focusing on supply flexibility, which we define as "the ability of the purchasing function to respond in timely and cost effective manner to changing requirements of purchased components, in terms of volume, mix and delivery date". Although some studies have recognized the influence of sourcing practices on manufacturing flexibility (e.g. Narasimhan and Das, 2000; Jack and Raturi, 2002), supply flexibility has rarely been studied as a separate construct. Furthermore, the drivers (reasons why supply flexibility is needed) and the sources (how supply flexibility is achieved) have been seldom studied simultaneously, and even when this has been done, the approach used was mostly theoretical (e.g. Duclos et al., 2003). Following the sequence of investigation previously found in the manufacturing flexibility literature, research focus should move from theoretical frameworks to empirical studies. Future studies should focus on construct validation, using different methods, such as interviews, case studies, and surveys (e.g. Jack and Raturi, 2002; Koste et al., 2004).

Hence, the aim of this paper is to empirically study the supply flexibility construct. More specifically, we aim at answering the following research questions:

1. Why do firms in different sectors increase supply flexibility? In other words: What are the drivers of supply flexibility?

2. How do firms in different sectors increase supply flexibility? In other words: What are the sources of supply flexibility? 
3. Which are the factors that affect how companies achieve supply flexibility?

4. Is there any relationship between the drivers and sources of supply flexibility?

In order to answer these research questions, we first performed a literature review on supply chain flexibility and related topics. As a second step, we carried out an exploratory multiple case study, based on interviews with seven manufacturing firms in Spain.

The remainder of the paper is structured as follows. Section two briefly examines the literature on supply flexibility; section three describes the research methodology; section four and five present the research results; and section six draws the conclusions from the research and provides some managerial implications of this work.

\section{Literature review}

\section{Supply chain flexibility / agility}

Flexibility is "the ability to change or react to environmental uncertainty with little penalty in time, effort, cost or performance" (Upton, 1994). Most of the existing studies on the Operations Management area focus on manufacturing flexibility (see for example, Koste and Malhotra, 1999; Vokurka and O'Leary-Kelly, 2000; Jack and Raturi, 2002; Koste et al., 2004). However, the focus on this type of flexibility is insufficient to deal with an increasingly turbulent environment, as firms are connected through complex supply chains (Prater et al., 2001; Jack and Raturi, 2002; Narasimhan and Das, 2000). Supply chain flexibility is defined as the ability of the supply chain to react to environmental uncertainty with little penalty in time, effort, cost or performance.

Recent studies on Supply Chain Management started to recognize the importance of supply chain flexibility. Fisher (1997) made a distinction between physically efficient and market-responsive supply chains. The former focused on supplying a predictable demand at the lowest possible cost, and, therefore, required little supply chain flexibility. The latter aimed at responding quickly to an unpredictable demand, and, thus, required high supply chain flexibility. Christopher (2000) also made a distinction between physically efficient and market-responsive supply chains. He referred to them as lean and agile supply chains.

Supply chain agility has two main components: supply chain speed and flexibility. The former is the time necessary to ship or receive a good, while the latter is the degree to which a firm can adjust its supply chain speed, destinations and volume (Prater et al., 2001). In this paper we focus on flexibility. Beamon (1999) defined four supply chain flexibility types, based on Slack (1983): volume (the ability to change output level of products produced), delivery (the ability to change planned delivery dates), mix (the ability to change 
the variety of products produced) and new product (the ability to introduce new products). Nevertheless, there are still few studies on supply chain flexibility and they rarely have empirical support (Caniato et al., 2004).

Recently, several authors proposed some frameworks in which supply chain flexibility was analyzed in four dimensions: supply, manufacturing, distribution and product development (Swafford et al., 2000; Pujawan, 2004). Our study will focus on the first dimension: supply, which is analyzed in more detail in the next section.

\section{Supply Flexibility}

In previous studies, the terms supply and sourcing flexibility have been used indistinctively to designate similar constructs. For simplicity reasons, we will use the term supply flexibility. Swafford et al. (2000) defined sourcing flexibility as "the ability of the purchasing function to respond in a timely and cost effective manner to changing requirements of the purchased components". Swafford et al. (2000) proposed some measures of supply flexibility (see Table 1). These measures are essentially an adaptation of the manufacturing flexibility framework to the sourcing context. These measures include two dimensions of flexibility: range (number of states), and adaptability (ability to change from one state to another). This approach still lacks empirical support and content validity.

Table 1. Measures of sourcing flexibility

\begin{tabular}{|l|l|}
\hline Dimension & Measure \\
\hline \multirow{4}{*}{ Range } & Range of order sizes \\
\cline { 2 - 3 } & Range of delivery frequencies \\
\cline { 2 - 3 } & Number of different parts \\
\cline { 2 - 3 } & Number of supplier-buyer relationship options \\
\cline { 2 - 3 } Adaptability & Number of suppliers \\
\cline { 2 - 3 } & Level of strategic linkage between purchasing and manufacturing \\
\hline & Ability of purchasing to pool global demand for orders \\
\cline { 2 - 3 } & Ability to get order sizes changed \\
\cline { 2 - 3 } & Ability to get delivery schedules changed \\
\cline { 2 - 3 } & Ability to influence supplier performance \\
\cline { 2 - 3 } & Ability to change worldwide suppliers \\
\hline & Ability to get ECOs (Engineering Change Orders) implemented \\
\cline { 2 - 3 } & Ability to outsource technology \\
\cline { 2 - 3 } & Ability to sustain suppliers on a long term basis \\
\cline { 2 - 3 } & Ability to source globally \\
\hline
\end{tabular}

Source: Swafford et al. (2000) 
Duclos et al. (2003) offered a conceptual model of supply flexibility, which was defined as "the ability to meet the changing needs of customers, changing the supply of product, including mix, volume, product variations and new products". However, they did not provide performance measures for this construct. They also pointed out the necessity of crossindustry, empirical studies that could give deeper insights about what constitutes flexibility in different industries.

Pujawan (2004) presented some items to assess supply flexibility (see Table 2). These items were proposed based on the following idea: "The sourcing function is said to be flexible if it has sufficient extra capacity to anticipate sudden increases in volume of materials acquired, and the suppliers are able to deliver materials in various different speed options and to mix different items into a delivery load so that small requests can be satisfied easily" (Pujawan, 2004).

\section{Table 2. Sourcing flexibility assessment}

\begin{tabular}{|l|}
\hline \multicolumn{1}{|c|}{ Question } \\
\hline Q1: Does the company have more than one qualified supplier for each item? \\
\hline Q2: Are the costs incurred to switch the purchase of item from one supplier to another low for most cases? \\
\hline Q3: Do most suppliers have the capability of supplying various different types of items? \\
\hline Q4: Is there a large extra total supply capacity for most items? \\
\hline Q5: Are most suppliers capable of producing a small quantity due to low setup costs? \\
\hline Q6: Are most suppliers capable of producing a large quantity of items in a short period of time? \\
\hline Q7: For most items, are multiple modes of transportation available to deliver the items from the suppliers? \\
\hline $\begin{array}{l}\text { Q8: Are both minimum order quantity, as well as multiple order quantity small, or LTL (less-than-truckload) } \\
\text { delivery policy available for most items? }\end{array}$ \\
\hline Q9: Is it technically and economically possible to mix different items into a delivery load? \\
\hline $\begin{array}{l}\text { Q10: Are most suppliers able to deliver urgent delivery requests with faster modes of transportation where } \\
\text { such a policy incurs reasonably low extra costs? }\end{array}$ \\
\hline
\end{tabular}

Source: Pujawan (2004)

\section{Flexibility drivers and sources}

A flexibility driver is "a factor that determines the need for flexibility" (Pujawan, 2004). We define supply flexibility driver as a supply chain characteristic over which the purchasing function has little or no control, and which determines the level of supply flexibility required. Some flexibility drivers could be: demand volatility, fluctuations in the production schedule, etc. If we consider a very simple supply chain (see Figure 1), we can appreciate that supply flexibility drivers can be internal (related to the characteristics of the focal company) or external (related to the characteristics of its upstream and/or downstream supply chains). 
Demand volatility and seasonality are examples of external downstream drivers while low component commonality (among the products of the company) is an example of internal driver. And, incomplete supplies are an example of upstream external driver.

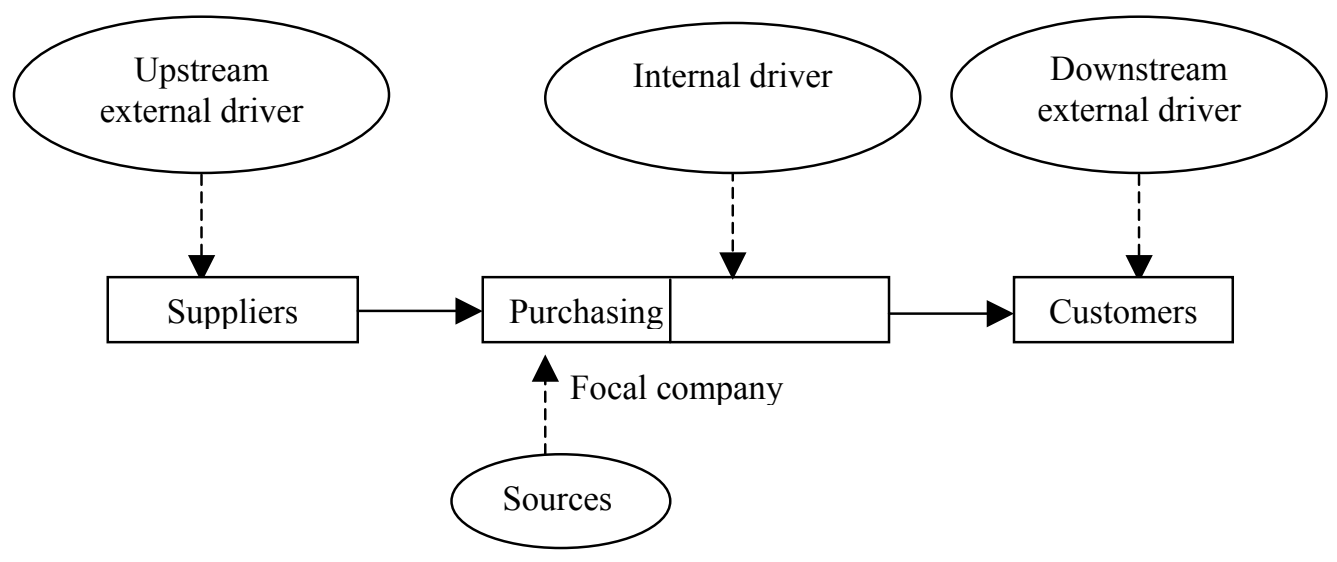

Figure 1. Supply flexibility drivers and sources

Flexibility drivers can be related to different types of uncertainty: volume, mix and delivery (Slack, 1983; Beamon, 1999; Christopher, 2000; Van Donk and Van der Vaart, 2005):

- Volume uncertainty: The level of uncertainty related to (1) the actual volume demanded of a specific component and/or (2) the real volume of a component that will be received.

- Mix uncertainty: The level of uncertainty related to the exact mix / specification of a component.

- Delivery uncertainty: The level of uncertainty related to the date in which the component will be (1) needed and/or (2) received.

For example, demand volatility and uncomplete supplies are examples of volume uncertainty. Frequent changes in a production schedule that has been sent to a supplier are related to volume, mix and delivery uncertainty. If these frequent changes in the production schedule are in mix and dates, and not in quantities (which may have been frozen for a particular time window), frequent changes in the production schedule is related only to mix and delivery uncertainty.

Jack and Raturi (2002) defined flexibility sources as "specific actions to generate flexibility". According to this, we define supply flexibility source as a purchasing function's practice or capability that allows an increase in supply flexibility. For example, a supply 
flexibility source could be the practice of establishing single-sourcing contracts with key suppliers co-located.

Supply flexibility sources are closely related to the type of sourcing strategy. Pyke and Johnson (2003) suggested that firms should select between strategic alliances (long-term partnerships, few suppliers, high multifunctional interaction, cooperative relationships) and eProcurement (short-term bids, larger supply base, Internet transactions, competitive relationships). They argued that the decision between both strategies should be based on four factors: strategic importance of the component, number of suppliers that can provide the component, supply chain complexity (e.g. complexity of the inbound logistics process) and supply uncertainty (in terms of cost, quality, flexibility, etc). They proposed that strategic alliances are more recommended when the purchased material is strategically important, there is only one supplier available, the supply chain is complex, and there is high supply uncertainty. Accordingly, eProcurement is preferred when the purchased material is not strategically important, there are many suppliers available, the supply chain is not complex, and supply uncertainty is low. Pyke and Johnson (2003) related the sourcing strategy (source) to the upstream supply chain uncertainty (driver). In our study we analyze how to increase supply flexibility using different practices in the purchasing function (among them, the sourcing strategies).

We believe that the practices used to increase supply flexibility might be related to the reason why there is a need for this type of flexibility; in other words, we believe that there is a relationship between the sources and drivers of supply flexibility. For this reason, it is very important to consider both (drivers and sources) simultaneously. In the literature, most of the existing studies do not consider the drivers and sources of supply flexibility simultaneously. Only Pujawan (2004) considered a framework for assessing flexibility requirements (in delivery, production, product development and supply) using different items (see Table 2 for the supply flexibility items) and, simultaneously, provided a list of flexibility drivers (factors behind the need of flexibility). The author provided this list of drivers because to assess the degree of flexibility requirements one should be able to assess each of the supply flexibility drivers. For example, the length of product life cycle (which is a flexibility driver) affects the need of three flexibility dimensions: product development, production and supply. Pujawan (2004) talks about drivers and flexibility requirements.

We share with Pujawan (2004) the framework of analyzing sources and drivers simultaneously. However, there are some major differences between both works. Firstly, Pujawan (2004) considers supply chain flexibility in supply, production, product delivery and 
product development, while we focus on supply flexibility. Secondly, Pujawan (2004) provided a guideline for conducting flexibility assessment and, in an attempt to assess the model validity, he conducted a case study; while our paper is an empirically-based study aiming at exploring the drivers and sources of supply flexibility. Thirdly, Pujawan (2004) considered that different drivers may imply different flexibility requirements while we consider that different drivers may imply different ways to achieve supply flexibility. Finally, our paper also studies other factors, such as supplier searching and switching costs and the type of uncertainty, which affect the selection of a particular supply flexibility strategy.

\section{Methodology}

This is clearly a research aiming theoretical development, as there are few studies on this area and there is not a consensual framework for analyzing supply flexibility. Due to the exploratory nature of this paper and the need to obtain an in depth knowledge of the drivers (reasons to increase supply flexibility) and the sources (how do firms increase supply flexibility?) and the relationship between drivers and sources, we adopted the case study methodology, as recommended by Yin (1984) and Eisenhardt (1989). The case study methodology is also very useful when the research aims at answering "why" and "how" questions (Yin, 1984). This methodology has also been greatly endorsed by operations management researchers (Voss et al., 2002). The process followed to design and implement this methodology has been adapted from Yin (1984).

The sample consisted of seven manufacturer firms belonging to different industries in Spain (fashion, consumer electronics, automotive and electrical machinery). We chose this sampling approach to increase the possibility of generalizing results and to explore withinindustry patterns. We selected firms in sectors with different requirements in terms of supply flexibility, ranging from highly volatile / uncertain sectors (e.g. fashion apparel) to more stable ones (e.g. electrical machinery). We also selected a heterogeneous sample of firms according to size. This allows obtaining sounder theoretical insights and more consistent validation of results. The profile of the studied firms is shown in Table 3. 
Table 3. Firms profile

\begin{tabular}{|l|l|l|l|}
\hline \multicolumn{1}{|c|}{ Sector } & \multicolumn{1}{|c|}{ Firm } & \multicolumn{1}{c|}{$\begin{array}{c}\text { Revenue } \\
\text { (Euros) }\end{array}$} & \multicolumn{1}{c|}{ Product } \\
\hline \multirow{3}{*}{ Automotive } & Manufacturer 1 & 51 Million & Steering columns, shafts and gears \\
\cline { 2 - 4 } & Manufacturer 2 & 54 Million & Acoustic and thermal systems \\
\cline { 2 - 4 } & Manufacturer 3 & 841 Million & Automobiles \\
\hline Fashion apparel & Manufacturer 1 & 142 Million & Apparels and accessories \\
\hline \multirow{2}{*}{ Electronics } & Manufacturer 1 & 102 Million & Cathode-ray tubes \\
\cline { 2 - 4 } & Manufacturer 2 & 168 Million & TV sets \\
\hline Electrical equipment & Manufacturer 1 & 26 Million & Electric motors \\
\hline
\end{tabular}

Reviewing previous studies on supply flexibility (e.g. Swafford et al., 2000; Pujawan, 2004), we noted that they were not focused on a specific component, but on the whole range of parts purchased by a firm. Although this is a good approach for a conceptual framework, in more empirical and focused studies this makes it difficult to obtain meaningful results, since different components may require different levels of supply flexibility. Our approach was, in each firm, to focus on a specific purchased component, which was critical in terms of supply flexibility. This allowed us to obtain more depth and richness in the data. The unit of analysis in this study was the purchasing function, as suggested by Swafford et al. (2000). Specifically, we were interested on investigating how each firm responded to uncertainties in the purchased components requirements.

To maintain data consistency and improve richness in details, we used a semistructured interview approach (Yin, 1984). In each firm, the purchasing or logistics director was selected for a one-hour interview, according to his respective responsibilities. An adequate informant was defined to be a person with in-depth knowledge of the supply base, purchasing and inbound logistics processes.

In order to increase the reliability of the case study analysis, it was decided to create an interview protocol (see Appendix) and a case study database. The interviews were conducted between February and March of 2005. Also, other sources of evidence such as industry databases, newspaper clippings and company websites were used to corroborate and augment evidence.

\section{Within-case analysis}

The objective of this analysis is to obtain familiarity with data and preliminary theory generation (Eisenhardt, 1989). For each firm, we briefly describe the drivers and sources of supply flexibility. 
Automotive sector: Case 1 (Steering columns, shafts and gears)

- Drivers: As in most automotive suppliers, there is considerable demand uncertainty in terms of product mix and delivery, but there is not much volume uncertainty. For the critical product, production schedule (mix and delivery) uncertainty is an important driver of flexibility, since the production department changes the delivery date and the specifications of the material very frequently.

- Sources: This firm uses a single sourcing policy for its critical material, due to commercial advantages when negotiating large volumes. In most cases the firm keeps a safety stock (from 1 to 3 days of production). For the delivery process, there is an agreement with a logistic provider, which manages a "milk run" process: every day, a truck collects the materials from several suppliers and transports them to a distribution center or directly to the production facilities. In some cases, suppliers have two deliveries at the same day. This can be done because suppliers are located near the firm's facilities. Internal collaboration (i.e. between departments, as defined by Stank et al., 2001) is a source of supply flexibility, mainly in the supplier selection process (by including all affected areas in the selection of potential suppliers). To increase supply flexibility, the firm also establishes long-term relationships with its suppliers and share with them delivery forecasts.

\section{Automotive sector: Case 2 (Acoustic and thermal systems)}

- Drivers: There are many raw material specifications. Fibers, for example, can be made of two different materials (polyester or polypropylene), eight colors, and four thickness levels. As a result, the firm must purchase about sixty different types of fibers. This increases the need for mix flexibility, since the firm cannot know in advance which type of fiber will be needed, and keeping large inventories for each type is expensive.

- Sources: There are no long-term supply contracts. Nevertheless, the suppliers have a longterm relationship with the company. In general, there are two or three main suppliers for each material, and they compete for each purchase. This is possible because raw material is highly standardized and the cost of switching suppliers is very low. The level of cooperation with suppliers is very low. However, the firm sends to them delivery forecasts. Suppliers are located mainly in Europe, which increases flexibility in supply. The firm maintains a safety stock correspondent to 1.5 months of demand, which reduces order fluctuations. 


\section{Automotive sector: Case 3 (Automobiles)}

- Drivers: The required supply flexibility is different according to the category of the supplier. The fifty most important suppliers are the modules assemblers, which supply on a JIT system. The rest of the first-tier suppliers can send their parts to the firm's warehouse or to one of the JIT suppliers. The required supply flexibility is higher for the JIT suppliers. Sudden changes on the production schedule (mainly delivery schedules and product mix) are the main source of delivery problems with these suppliers.

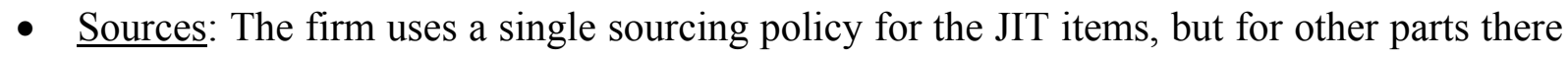
is more than one supplier. The suppliers, in this latter case, compete for each purchase. Contracts are long-term, i.e., are signed for the whole life cycle of each product - up to seven years. Nevertheless, the performance of supplier is checked annually, and if the supplier is not achieving performance goals, the supplier is changed. As flexibility requirements are higher for the JIT suppliers, we will focus on the analysis of how the automotive firm increases supply flexibility of the components supplied by these firms. The JIT suppliers are located in a supplier park, i.e. a manufacturing area around the factory (in some cases within walking distance). Suppliers assemble their modules and synchronize their deliveries with the manufacturer production schedule. As a result, suppliers increase their delivery flexibility. Another source of flexibility comes from the exhaustive supplier selection process, in which suppliers' responsiveness capability is a key element. The automotive firm also implements other common practices to increase supply flexibility: to send delivery forecasts to suppliers and to use supplier collaboration on product development. Internal integration with the production department helps increasing supply flexibility, because it allows the purchasing area to promptly detect and respond to manufacturing needs (e.g. changes in the specification of the materials).

\section{Fashion apparel sector (Apparels and accessories)}

- Drivers: The main driver is demand seasonality (volume uncertainty): winter is the most intense sales period, thus production is intensified during the middle of the year and reduced substantially in other months. Moreover, as with other firms in this sector, it is very difficult to forecast the sales for each season, which increases the need for supply flexibility (in terms of volume and mix). The demand volatility during high season, the forecast accuracy, the slack production capacity, the low product commonality (i.e. the same raw material cannot be used in many products) and the unresponsive suppliers are also important drivers. Regarding the unresponsiveness of some of its suppliers, it has to be stated that the company cannot 
switch suppliers as quickly as competitors do, because of environmental and social corporate policies (e.g. new suppliers must comply with environmental regulations).

- Sources: The firm admits a safety stock of $10 \%$ of demand, to cope with long and variable supply lead-times. Recently, there has been a redesign of the logistics process: suppliers now deliver the fabric directly to the outsourced manufacturing facilities, instead of an intermediate stage at the Distribution Center. To increase the supply flexibility, the firm follows a multiple sourcing strategy (it has multiple suppliers for a particular item), has longterm relationships with most of its suppliers and shares delivery forecasts with them. To increase supply flexibility the company is also trying to reduce the time it takes to switch unresponsive suppliers.

\section{Consumer electronics sector: Case 1 (Cathode-ray tubes)}

- Drivers: The critical raw material is glass. Demand uncertainty (in terms of mix and delivery) is considerable. The production plan is revised on a weekly basis, but modifications within the week are not uncommon. Moreover, the high level of customization of the final products (there are about thirty different glass specifications, one for each customer / model) increases the need for mix flexibility at the component level.

- Sources: Traditionally, the company adopted a multiple sourcing policy, with suppliers located worldwide. Nevertheless, some critical items (such as glass) are now supplied by a single firm in order to achieve benefits on commercial conditions. This happens because of the rise in the price of commodities. Although there is an official policy of "no stocks", in practice there is a safety stock proportional to the interval between purchases. The glass supplier was selected based on an exhaustive process, where its responsiveness capability was as important as its cost. Internal integration with the production department (to reduce production schedule fluctuations), the sharing of delivery forecasts with suppliers and longterm supply relationships with suppliers are also important sources of supply flexibility.

\section{Consumer electronics sector: Case 2 (TV sets)}

- Drivers: Demand volatility (in terms of volume and product mix) is very high. There are many different types of TV sets (around 100), due to different options of colors, technical specifications, etc. Sales forecasts are not very accurate: the margin of error is $40 \%$, which increases the need for supply flexibility for the most critical item (i.e. the microprocessor). Another main driver is the low commonality of microprocessors. Each customer requires a 
different technical specification, and thus, a different type of microprocessor (from a total of twenty options) is needed for each customer. As microprocessor types are not interchangeable, a high level of mix flexibility is required from the suppliers.

- Sources: There are no long-term contracts with suppliers. However, relationships with suppliers are mostly long-term, and the firm shares delivery forecasts with them. Flexibility in supply transportation modes is important (i.e. regular deliveries are shipped by sea, but urgent deliveries may be shipped by plane). There are two microprocessor suppliers, both located in Europe. The supplier searching and switching process is very fast: only three months, which means that the firm can change its supply base for a certain component four times a year, if necessary. Other sources of supply flexibility are the joint product development of microprocessors, and inventory buffers at the focal company.

\section{Electrical equipment sector (Electric motors)}

- Drivers: Although in general fluctuations in demand (in terms of volume, mix, or delivery) are not high, the company keeps some safety stock to protect against these fluctuations. There is an annual sales forecast, which is sent to suppliers, but every week, purchase orders are sent to them. Purchase order changes within the week may happen, but are not common. Therefore, required supply flexibility is very low.

- $\underline{\text { Sources: }}$ There is a safety stock to protect against demand fluctuations. There are no longterm supply contracts, although relationships with suppliers are mostly long-term. $70 \%$ of the suppliers are located in Spain. Single sourcing is used for the critical items. The firm usually sends delivery forecasts to suppliers.

\section{Cross-case analysis}

\section{Drivers}

A supply flexibility driver is a supply chain characteristic over which the purchasing function has little or no control, and which determines the level of supply flexibility required. We have identified internal drivers (characteristics of the focal company) and external drivers (characteristics of its upstream and/or downstream supply chains). Table 4 summarises the results of the case studies. Regarding the internal drivers we have found the following:

- Production schedule uncertainty: Defined as the uncertainty regarding production plans in the short run (mainly in terms of delivery and mix). 
- Low component commonality: Defined as the extent to which the same purchased component can be used in several final products. It basically affects the required mix flexibility, although recent studies have suggested that it has an indirect effect over volume flexibility (Salvador et al., 2005).

- JIT purchasing: Defined as the use of small purchasing batches and frequent deliveries, transferring the inventory from the manufacturer to the supplier (Ponce and Prida, 2004). This practice increases the required mix and delivery flexibility.

- Manufacturer slack capacity: Defined as the difference between the manufacturer maximum output rate and the normal production rate (Jack and Raturi, 2002). It affects basically the required volume flexibility.

The downstream supply chain drivers identified are:

- Demand volatility: Defined as the variability of the manufacturer customer's demand, in terms of volume and mix.

- Demand seasonality: Defined as the extent to which the manufacturer customer's demand is concentrated in the same periods every year. This driver has a direct impact over the required level of volume flexibility (Jack and Raturi, 2002).

- Forecast accuracy: Defined as the deviation of customer's actual demand from sales forecast (Stratton and Warburton, 2003). This driver affects mainly volume and product mix flexibility.

And, finally, regarding the upstream supply chain drivers we only found the following one:

- Non-responsive suppliers: Defined as the use of suppliers who do not send the right quantities in the established dates. It basically affects the volume, mix and delivery flexibility.

Table 4. Supply flexibility drivers

\begin{tabular}{|c|c|c|c|c|c|c|c|c|}
\hline \multirow{2}{*}{$\begin{array}{l}\text { Position in } \\
\text { the supply } \\
\text { chain }\end{array}$} & \multirow{2}{*}{ Driver } & \multicolumn{3}{|c|}{ Automotive } & \multirow{2}{*}{\begin{tabular}{|c|}
$\begin{array}{c}\text { Fashion } \\
\text { apparel }\end{array}$ \\
1 \\
\end{tabular}} & \multicolumn{2}{|c|}{$\begin{array}{l}\text { Consumer } \\
\text { electronics }\end{array}$} & \multirow{2}{*}{$\begin{array}{c}\begin{array}{c}\text { Electrical } \\
\text { equipment }\end{array} \\
1\end{array}$} \\
\hline & & 1 & 2 & 3 & & 1 & 2 & \\
\hline \multirow{4}{*}{ Internal } & Production schedule uncertainty & $\mathrm{x}$ & & $\mathrm{x}$ & & $\mathrm{x}$ & & \\
\hline & Low component commonality & & $\mathrm{x}$ & & $\mathrm{x}$ & $\mathrm{x}$ & $\mathrm{x}$ & \\
\hline & JIT purchasing & & & $\mathrm{x}$ & & & & \\
\hline & Slack capacity at focal company & & & & $\mathrm{x}$ & & & \\
\hline \multirow{3}{*}{ Downstream } & Demand volatility & & & & $\mathrm{x}$ & $\mathrm{x}$ & $\mathrm{x}$ & \\
\hline & Demand seasonality & & & & $\mathrm{x}$ & & & \\
\hline & Low forecast accuracy & & & & $\mathrm{x}$ & & $\mathrm{x}$ & \\
\hline Upstream & Unresponsive suppliers & & & & $\mathrm{x}$ & & & \\
\hline
\end{tabular}


This list of drivers differs slightly from the supply flexibility drivers proposed by Pujawan (2004). In our study we observed that sometimes the uncertainties that drive the required supply flexibility are actually introduced by the focal company (e.g. changing frequently the production schedule). This is in line with recent empirical studies in build-toorder supply chains (Krajewski et al., 2005). This means that the focal company can reduce the required supply flexibility by changing some practices. Some of these practices are internal to the company but not under the control of the purchasing area. For example, automotive firm \#3 reduced the delivery flexibility required from its suppliers by freezing a part of its production schedule. Freezing a part of the production schedule was a decision to be taken by the production area (it was not under the control of the purchasing area). All internal drivers (Production schedule uncertainty, low component commonality, JIT purchasing and manufacturer slack capacity) are not under the control of the purchasing area but under the control of the other departments or functional areas of the company. This means that in order to reduce the required supply flexibility the company could take some actions.

Regarding the internal drivers we have to make the following observation: the production schedule uncertainty is a driver only present in make-to-order or assemble-toorder environments. The companies interviewed that were working with forecasts and a make-to-stock environment did not mention this driver. In future studies we should add to the internal driver construct the type of production environment (make-to-stock, assemble-toorder, make-to-order).

As far as external drivers are concerned, it has to be said that there are more downstream drivers than upstream. Drivers related to demand uncertainty (demand volatility and low forecast accuracy) are the most important ones. Upstream drivers relate to the uncertainty in the suppliers' delivery (e.g. the supplier does not deliver the quantities ordered, or it does not meet the date agreed, etc). As it can be appreciated in Table 4, only one company mentioned unresponsiveness of suppliers as a driver. This result was expected, since the reliability of a supplier is a prerequisite to becoming a supplier.

When analyzing Table 4, we can observe a balance between internal and external drivers. An important exception was the automotive sector, in which internal drivers seem to be more important than external ones. External downstream drivers are not so important because customer demand is not as volatile and hard to predict, as in other sectors (e.g. fashion apparel). On the other hand, internal drivers are important in this sector because JIT purchasing is feasible only if the manufacturer generates stable delivery plans (Ponce and Prida, 2004). 
We saw no significant driver for the electrical equipment company. This was expected, since it is working on a more stable industry: less demand fluctuations, easier production planning and less complex product structure.

We also noted that some drivers seem to be sector-specific (e.g. JIT purchasing for automotive and demand seasonality for fashion apparel). This was also expected, given the specificities in the sourcing practices adopted and the patterns of demand in each industry. Nevertheless, it is interesting to observe that some other drivers (e.g. low component commonality and demand volatility) apparently affect several sectors.

In Table 5 we have classified the drivers taking into account the type of uncertainty generated, based on the literature review and empirical verification in the firms studied. For example, production schedule fluctuations may cause mix and delivery uncertainties, because the exact definition of the component specification and delivery date is delayed until the last moment. Volume uncertainty, however, is less affected by production schedule fluctuations, because volume decisions are based on aggregate forecasts (e.g. total quantity to be produced), which are usually more precise than forecasts at the SKU level (Simchi-Levi et al., 2002).

Table 5. Supply flexibility drivers and type of uncertainty

\begin{tabular}{|l|c|c|c|}
\hline \multirow{2}{*}{\multicolumn{1}{|c|}{ Driver }} & \multicolumn{3}{c|}{ Type of uncertainty } \\
\cline { 2 - 4 } & Volume & Mix & Delivery \\
\hline Production schedule uncertainty & & $\mathrm{x}$ & $\mathrm{x}$ \\
\hline JIT purchasing & & $\mathrm{x}$ & $\mathrm{x}$ \\
\hline Unresponsive suppliers & $\mathrm{x}$ & $\mathrm{x}$ & $\mathrm{x}$ \\
\hline Low component commonality & $\mathrm{x}$ & $\mathrm{x}$ & \\
\hline Demand volatility & $\mathrm{x}$ & $\mathrm{x}$ & \\
\hline Low forecast accuracy & $\mathrm{x}$ & $\mathrm{x}$ & \\
\hline Demand seasonality & $\mathrm{x}$ & & \\
\hline Slack capacity at focal company & $\mathrm{x}$ & & \\
\hline
\end{tabular}

\section{Sources}

The sources detected to increase the supply flexibility of a specific component can be classified into two strategies: Increase suppliers' responsiveness and flexible sourcing (see Table 6):

- Increase suppliers' responsiveness. This first group includes practices that aim at increasing the supplier responsiveness capabilities, such as suppliers' short-term process flexibility (i.e. "the ability to efficiently change schedules on a frequent 
basis", (Krajewski et al., 2005)), or a supplier's ability to produce efficiently in small quantities (Fisher et al., 1997). Single sourcing, geographical proximity of suppliers, suppliers selected based on flexibility, internal collaboration (e.g. between the purchasing and production departments) and process integration with logistics providers are important elements of this strategy. This strategy is common in the automotive sector, mainly in the relationship with first-tier suppliers. The firms that apparently adopt this strategy are the automotive firms $\# 1$ and $\# 3$, the consumer electronics firm \#1 and the electrical equipment firm.

A fundamental element of this strategy is single sourcing. There is evidence that suggests a relationship between single sourcing and supplier flexibility. Rossetti and Choi (2005), in a recent study about strategic sourcing in the aerospace industry, argued that supplier flexibility capability plays a crucial role in sole sourcing agreements. Another important decision of some firms that follow this strategy is the co-location of strategic suppliers in areas called supplier parks, which has created increasing interest in the academic debate (Reichhart and Holweg, 2005).

- Flexible sourcing: The second strategy is to adopt a larger supplier base, and constantly reconfigure the supply chain (Zeng, 2000; Duclos et al., 2003). In this case, the main source of supply flexibility is not a particular supplier's responsiveness capability, but the leading firm's ability of coordinating the entire supply chain and redesigning the supply network quickly and at a low cost. Suppliers are not located as close as in the first strategy. Actually, studies suggest that lower-cost suppliers located further away may be more responsive than suppliers close to the market, since low wage rates enable suppliers to afford excess capacity that compensates for longer transportation times (Fisher et al., 1997). The firms that seem to adopt such a strategy are the automotive firm $\# 2$, the fashion apparel firm and the consumer electronics firm $\# 2$.

This classification ("increase suppliers' responsiveness" and "flexible sourcing") is in line with previous segmentations of sourcing strategies, i.e. strategic alliances or eprocurement (Pike and Johnson, 2003), "Strategic" or "Leverage" components (Kraljic, 1983), and "strategic" or "market exchange" dyadic relationships (Bensaou, 1999). Nevertheless, none of these previous frameworks focused on supply chain uncertainties (e.g. demand volatility, production schedule uncertainty, etc). Moreover, they did not relate explicitly supplier segmentation and corresponding impacts on supply flexibility. 
We have found a third group of sources that seems to be applied in both strategies. Most of the companies have inventory buffers, establish long-term relationships with their suppliers and share forecasts with them. Most of these are consolidated practices in different sectors, and provide supply flexibility in any of the both strategies mentioned previously. Another common practice to both strategies is "joint product development". However, only few of the companies interviewed develop their products with their suppliers.

According to these results we establish the following propositions, which should be studied in further studies:

Proposition 1. Firms use two strategies to increase their supply flexibility: "increase supply flexibility" and "flexible sourcing". The former is characterized by single sourcing, a high level of internal and external integration, co-location of suppliers and supplier selection based on supplier' responsiveness capability. The latter is characterized by a larger supply base, lower levels of supplier responsiveness and faster supply network redesign.

Proposition 2. Some sources of supply flexibility are employed by firms using both strategies: inventory buffers, long-term relationships with suppliers, share forecasts with suppliers and joint product development.

Table 6. Supply flexibility sources

\begin{tabular}{|c|c|c|c|c|c|c|c|c|}
\hline \multirow{2}{*}{$\begin{array}{l}\text { Supply flexibility } \\
\text { strategy }\end{array}$} & \multirow[t]{2}{*}{ Source } & \multicolumn{3}{|c|}{ Automotive } & \multirow{2}{*}{$\begin{array}{c}\begin{array}{c}\text { Fashion } \\
\text { apparel }\end{array} \\
1\end{array}$} & \multicolumn{2}{|c|}{$\begin{array}{l}\text { Consumer } \\
\text { electronics }\end{array}$} & \multirow{2}{*}{$\begin{array}{c}\begin{array}{r}\text { Electrical } \\
\text { equipment }\end{array} \\
1\end{array}$} \\
\hline & & 1 & 2 & 3* & & 1 & 2 & \\
\hline \multirow{5}{*}{$\begin{array}{l}\text { Increase suppliers } \\
\text { responsiveness }\end{array}$} & Single sourcing & $\mathrm{x}$ & & $\mathrm{x}$ & & $\mathrm{x}$ & & $\mathrm{x}$ \\
\hline & Suppliers selected based on flexibility & & & $\mathrm{x}$ & & $\mathrm{x}$ & & \\
\hline & Internal collaboration & $\mathrm{x}$ & & $\mathrm{x}$ & & $\mathrm{x}$ & & \\
\hline & Integration with logistic provider & $\mathrm{x}$ & & & & & & \\
\hline & Co-location of suppliers & $\mathrm{x}$ & & $\mathrm{x}$ & & & & $\mathrm{x}$ \\
\hline \multirow{3}{*}{ Flexible sourcing } & Multiple suppliers & & $\mathrm{x}$ & & $\mathrm{x}$ & & $\mathrm{x}$ & \\
\hline & Alternative transportation modes & & & & & & $\mathrm{x}$ & \\
\hline & $\begin{array}{l}\text { Reduce time to switch unresponsive } \\
\text { suppliers }\end{array}$ & & & & $\mathrm{x}$ & & & \\
\hline \multirow{4}{*}{ Both } & $\begin{array}{l}\text { Joint product development with } \\
\text { suppliers }\end{array}$ & & & $\mathrm{x}$ & & & $\mathrm{x}$ & \\
\hline & Send delivery forecasts to suppliers & $\mathrm{x}$ & $\mathrm{x}$ & $\mathrm{x}$ & $\mathrm{x}$ & $\mathrm{x}$ & $\mathrm{x}$ & $\mathrm{x}$ \\
\hline & Long-term relationship with suppliers & $\mathrm{x}$ & $\mathrm{x}$ & $\mathrm{x}$ & $\mathrm{x}$ & $\mathrm{x}$ & $\mathrm{x}$ & $\mathrm{x}$ \\
\hline & Inventory buffers at the focal company & $\mathrm{x}$ & $\mathrm{x}$ & & $\mathrm{x}$ & $\mathrm{x}$ & $\mathrm{x}$ & $\mathrm{x}$ \\
\hline
\end{tabular}


Furthermore, firms may act concurrently on the supply flexibility drivers in order to reduce the required supply flexibility. For example, the electronics firm \#2, apart from adopting a flexible sourcing strategy, is increasing the parts commonality; and, the automotive firm \#3, apart from adopting the "increase suppliers' responsiveness" strategy, has reduced the required supply flexibility by increasing the frozen part of the production schedule. This means that companies can reduce the supply flexibility gap (difference between the supply flexibility required and the supply flexibility achieved) by (1) reducing the supply flexibility required by working on the drivers and/or (2) increasing the supply flexibility by implementing a "flexible sourcing” or a "increase suppliers' responsiveness" strategy.

The selection between the "increase suppliers' responsiveness" and "flexible sourcing" strategies seems to be affected by two factors: the supplier searching and switching costs, and the type of uncertainty.

We define supplier searching and switching costs as the costs associated to finding, certifying and switching a supplier, without significant decrease in performance (in terms of cost, quality and price). These costs can be estimated by the buyer's specific investments in relation to the supplier (Bensaou, 1999). These can be (1) tangible investments in buildings or physical assets dedicated to the components of a specific supplier, (2) internal processes customized to the components produced by this supplier, or (3) time and effort dedicated to learn supplier's business processes and nurture the relationship.

Based on the results of the case studies (which are summarised in Table 7), we propose that when supplier searching and switching costs are low, companies can increase supply flexibility by implementing a "flexible sourcing" strategy; but, when these costs are high, companies increase supply flexibility by implementing a "supplier responsiveness" strategy. In our case studies, the consumer electronics firm \#2, which can search and switch suppliers quickly (in less than three months), uses a "flexible sourcing" strategy. On the other hand, automotive firm \#3, which has high supplier switching costs (due to supplier-specific investments), adopts an "increase supplier responsiveness" strategy. According to this, we establish the following propositions:

Proposition 3. The supplier searching and switching costs influence the selection of the supply flexibility strategy.

(a) When supplier searching and switching costs are high, firms select the “increase supplier responsiveness” strategy.

(b) When supplier searching and switching costs are low, firms select the "flexible sourcing" strategy. 
Table 7. Drivers, type of uncertainty, switching costs and sources

\begin{tabular}{|c|c|c|c|c|c|c|c|c|c|c|}
\hline & 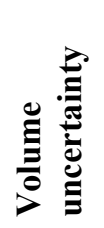 & 咅 & 窇 & 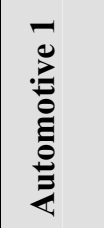 & 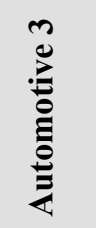 & 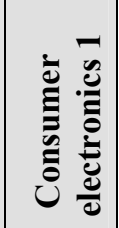 & 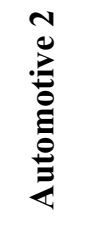 & 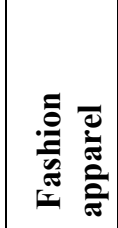 & 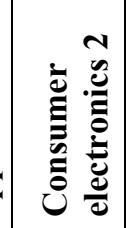 & 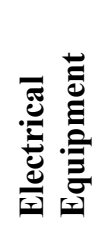 \\
\hline \multicolumn{11}{|l|}{ Drivers } \\
\hline $\begin{array}{l}\text { Production schedule } \\
\text { uncertainty }\end{array}$ & & $\mathrm{x}$ & $\mathrm{x}$ & $\mathrm{x}$ & $\mathrm{x}$ & $\mathrm{x}$ & & & & \\
\hline JIT purchasing & & $\mathrm{x}$ & $\mathrm{x}$ & & $\mathrm{x}$ & & & & & \\
\hline Unresponsive suppliers & $\mathrm{x}$ & $\mathrm{x}$ & $\mathrm{x}$ & & & & & $\mathrm{x}$ & & \\
\hline Low component commonality & $\mathrm{x}$ & $\mathrm{x}$ & & & & $\mathrm{x}$ & $\mathrm{x}$ & $\mathrm{x}$ & $\mathrm{x}$ & \\
\hline Demand volatility & $\mathrm{x}$ & $\mathrm{x}$ & & & & $\mathrm{x}$ & & $\mathrm{x}$ & $\mathrm{x}$ & \\
\hline Low forecast accuracy & $\mathrm{x}$ & $\mathrm{x}$ & & & & & & $\mathrm{x}$ & $\mathrm{x}$ & \\
\hline $\begin{array}{l}\text { Slack capacity at focal } \\
\text { company }\end{array}$ & $\mathrm{x}$ & & & & & & & $\mathrm{x}$ & & \\
\hline Demand seasonality & $\mathrm{x}$ & & & & & & & $\mathrm{x}$ & & \\
\hline \multicolumn{11}{|l|}{ Switching costs } \\
\hline & & & & $\uparrow \uparrow$ & $\uparrow \uparrow$ & $\uparrow \uparrow$ & $\downarrow$ & $\downarrow$ & $\downarrow$ & $\bar{\uparrow}$ \\
\hline \multicolumn{11}{|l|}{ Strategy implemented } \\
\hline & & & & 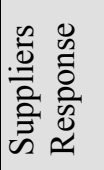 & 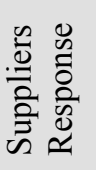 & 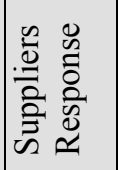 & 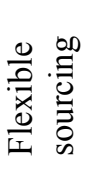 & 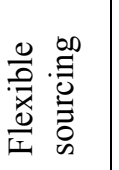 & 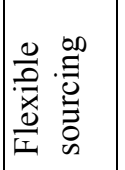 & \\
\hline
\end{tabular}

The second factor that seems to explain the selection of a supply flexibility strategy is the type of uncertainty (volume, mix or delivery). Table 7 summarizes the results of Tables 4 , 5 and 6, and suggests a relationship between the supply flexibility strategy adopted and the type of uncertainty. When there is delivery and mix uncertainty, firms apparently prefer the "increase supplier responsiveness" strategy. When the main driver of flexibility is the uncertainty in the production schedule (delivery and mix uncertainty), companies seem to increase flexibility by implementing a strategy aiming at "increasing the supplier responsiveness". On the other hand, firms seem to select the "flexible sourcing" strategy when there is volume and mix uncertainty. When the drivers of flexibility are: low component commonality, demand volatility and low forecast accuracy (volume and mix uncertainty), companies try to increase flexibility by implementing a "flexible sourcing" strategy. According to these results we establish the following propositions: 
Proposition 4. The type of downstream uncertainty influences the supply flexibility strategy adopted.

(a) When mix and delivery uncertainties are predominant, firms select the "increase supplier responsiveness" strategy.

(b) When volume and mix uncertainties are predominant, firms select the "flexible sourcing" strategy.

\section{Conclusions}

Our study shows that firms increase supply flexibility for different reasons, using different strategies. Supply flexibility drivers can be either external (demand volatility and seasonality, forecast accuracy) or internal to the firm (production schedule uncertainty, low component commonality, JIT purchasing and slack capacity at the focal company). The sources of supply flexibility can be classified into "increase suppliers' responsiveness" and "flexible sourcing", but both these strategies share some common practices (long-term relationships with suppliers, share forecasts with them, joint product development, and inventory buffers at the focal company).

Although most of these results were in line with the literature, it is surprising to observe that collaborative planning practices were not mentioned as important sources of supply flexibility. Firms collaborated with suppliers by sharing delivery forecasts, but the forecasting and delivery planning process were done individually (i.e. without suppliers involvement) in all firms studied. The reasons for that should be investigated in further studies.

Our contribution to the literature is twofold. Firstly, we have explored the relation between drivers and sources of supply flexibility. Results of the case study analysis suggest that this relation can be synthesized in the following propositions: When the main driver of flexibility is the uncertainty in the production schedule (mix and delivery uncertainty), companies can increase supply flexibility by implementing a strategy aiming at "increasing the supplier responsiveness". On the other hand, when the drivers of flexibility are: low component commonality, demand volatility and low forecast accuracy (volume and mix uncertainty), companies seem to increase supply flexibility by implementing a "flexible sourcing" strategy.

Our second contribution to the literature lies on the methodology adopted (multiple case study). As we pointed out, most of the previous studies on supply flexibility aimed at building conceptual frameworks and lacked empirical validation. Nevertheless, we believe 
that the supply flexibility concept will benefit considerably from the insights provided by real business problems and constraints faced by firms in different industrial sectors, like those presented in this study.

Moreover, we explored the possibility of combining two related lines of research: purchasing portfolio models and supply flexibility. Former studies on supplier segmentation did not have an explicit focus on supply flexibility issues. Similarly, we believe that supply flexibility studies still lack an appropriate segmentation of supply strategies. Although it was not the main objective of this study, initial results suggest that future studies in that line are recommended.

As many exploratory case studies, this paper has some limitations: The generalizability of results is questionable, since the sample of firms is not statistically significant. Also, there could be some sort of country bias, since only Spanish firms were investigated. Another difficulty is the subjective criterion for some variables, such as the production schedule uncertainty or the integration level. Despite these limitations, our study contributes to the existing literature by empirically investigating which are the main reasons why companies need to increase supply flexibility, how they increase this flexibility, and suggesting some factors that could influence the selection of a particular supply flexibility strategy.

We believe that this paper will be informative and insightful for professionals and researchers in the Supply Chain Management area: Professionals are provided with a list of drivers and sources of flexibility and with some guidelines about how to increase flexibility taking into account the reasons why this flexibility is needed. Researchers are provided with some preliminary lists of drivers and sources of flexibility, which should be further analyzed. Researchers are also given some further lines of research in the supply flexibility topic. Regarding this latter aspect, some lines of future research are:

- To test the abstract constructs of flexibility drivers and sources;

- To test the relationship between both constructs;

- To identify some variables that may affect the relationship between the drivers and the sources (e.g. supplier searching and switching costs). 


\section{References}

Beamon, B. (1999), "Measuring supply chain performance", International Journal of Operations and Production Management, Vol.19 No. 3, pp.275-292.

Bensaou, M. (1999), "Portfolios of buyer-supplier relationships”, Sloan Management Review, Vol. 40 No.4, pp.35-44.

Caniato, F., Spina, G. and Cagliano, R. (2004), "Supply chain flexibility: a taxonomy of strategies", Proceedings of the $11^{\text {th }}$ International EurOMA Conference, Fontainebleau, pp.115-124.

Christopher, M. (2000), "The Agile Supply Chain: Competing in Volatile Markets", Industrial Marketing Management, Vol.29 No.1, pp.37-44.

Duclos, L.K., Vokurka, R.J. and Lummus, R.R. (2003), “A conceptual model of supply chain flexibility", Industrial Management \& Data Systems, Vol.103 No.6, pp.446-456.

Eisenhardt, K.M. (1989), "Building theories from case study research", Academy of Management Review, Vol.14 No. 4, pp.532-550.

Ellram, L. and Carr, A. (1994), "Strategic purchasing: A History and Review of the Literature", International Journal of Purchasing and Materials Management, Vol. 30 No.2, pp.10-18.

Fisher, M.L. (1997), "What is the right supply chain for your product?”, Harvard Business Review, Vol.75 No.2, pp.105-116.

Fisher, M., Hammond, J., Obermeyer, W. and Raman, A. (1997), "Configuring a supply chain to reduce the cost of demand uncertainty", Production and Operations Management, Vol. 6, No. 3, pp. 211-225.

Gimenez, C. (2005), "Case studies and surveys in Supply Chain Management research - Two complementary methodologies", in Kotzab, H., Seuring, S., Muller, M., Reiner, G., 2005, Research methodologies in Supply Chain Management, Physica, Heidelberg, pp. 315-330.

Jack, E.P. and Raturi, A. (2002), "Sources of volume flexibility and their impact on performance", Journal of Operations Management, Vol.20 No.5, pp.519-548.

Koste, L.K. and Malhotra, M.K. (1999), "A theoretical framework for analyzing the dimensions of manufacturing flexibility", Journal of Operations Management, Vol.18 No.1, pp.75-93.

Koste, L.L, Malhotra, M.K. and Sharma, S. (2004), "Measuring dimensions of manufacturing flexibility", Journal of Operations Management, Vol.22 No.2, pp.171-196. 
Krajewski, L., Wei, J. and Tang, L.L. (2005), "Responding to schedule changes in build-toorder supply chains", Journal of Operations Management, Vol.23 No.5, pp. 452-469.

Kraljic, P. (1983), "Purchasing must become supply management", Harvard Business Review, Vol. 61, No. 5, pp.109-117.

Lee, H.L. (2002), “Aligning Supply Chain Strategies with Product Uncertainties”, California Management Review, Vol. 44 No.3, pp.105-119.

Lee, H.L., Padmanabhan, V. and Whang, S. (1997), "Information distortion in a supply chain: The Bullwhip Effect”, Management Science, Vol.43 No.4, pp.546-558.

Mentzer, J.T. and Flint, D.J. (1997), "Validity in logistics research", Journal of Business Logistics, Vol.18 No.1, pp.199-216.

Narasimhan, R. and Das, J. (2000), “An empirical examination of sourcing's role in developing manufacturing flexibility", International Journal of Production Research, Vol.38 No.4, pp.875-893.

Ponce, E. and Prida, B. (2004), La logística de aprovisionamientos para la integración de la cadena de suministros, Pearson Educación, Madrid.

Prater, E., Biehl, M. and Smith, M.A. (2001), "International supply chain agility: Tradeoffs between flexibility and uncertainty", International Journal of Operations and Production Management, Vol.21 No.5/6, pp.823-839.

Pujawan, N. (2004), “Assessing supply chain flexibility: a conceptual framework and a case study", International Journal of Integrated Supply Management, Vol.1 No.1, pp.7997.

Pyke, D.F. and Johnson, M.E. (2003), "Sourcing Strategy and Supplier Relationships: Alliances vs. eProcurement," in The Practice of Supply Chain Management. Kluwer Publishers, Boston.

Reichhart, A. and Holweg, M. (2005), "Towards a classification of supplier parks", Proceedings of the 12 $2^{\text {th }}$ International EurOMA Conference, Budapest, pp. 441-450.

Rossetti, C. and Choi, T.Y. (2005), "On the dark side of strategic sourcing: Experiences from the aerospace industry", Academy of Management Executive, Vol.19 No.1, pp.46-60.

Salvador, F., Rungtusanatham, M., Forza, C. and Trencin, A. (2005), "Understanding synergies and trade-offs between volume flexibility and mix flexibility in build-toorder strategies", Proceedings of the $12^{\text {th }}$ International EurOMA Conference, Budapest, pp. 1313-1322.

Simchi-Levi, D., Kaminsky, P., Simchi-Levi, E. (2002), Designing and Managing the Supply Chain: Concepts, Strategies and Case Studies, Mc-Graw-Hill/Irwin, Boston. 
Slack, N. (1983), "Flexibility as a manufacturing objective", International Journal of Operations and Production Management, Vol.7 No.4, pp.35-45.

Stank, T.P., Keller, S.B and Daugherty, P.J. (2001), "Supply chain collaboration and logistical service performance”, Journal of Business Logistics, Vol.22 No.1, pp.29-48.

Stevens, G.C. (1989), "Integrating the supply chain”, International Journal of Physical Distribution and Materials Management, Vol.19 No.8, pp.3-8.

Stratton, R. and Warburton, R.D.H. (2003), "The strategic integration of agile and lean supply", International Journal of Production Economics, Vol.85 No.2, pp.183-198.

Swafford, P., Ghosh, S. and Murthy, N. (2000), "A model of global supply chain agility and its impact on competitive performance", Proceedings of the $31^{\text {st }}$ National DSI Meeting, Orlando, Florida, pp.1037-1039.

Upton, D.M. (1994), “The management of manufacturing flexibility". California Management Review, Vol.36 No.2, pp.72-89.

Van Der Vaart, T. and Van Donk, D.P. (2004), "Buyer focus: Evaluation of a new concept for supply chain integration", International Journal of Production Economics, Vol.92 No.1, pp.21-30.

Van Donk, D.P. and Van der Vaart, T. (2005), “A case of shared resources, uncertainty and supply chain integration in the process industry", International Journal of Production Economics, Vol.96 No.1, pp.97-108.

Van Hoek, R., Harrison, A. and Christopher, M. (2001) "Measuring agile capabilities in the supply chain", International Journal of Operations and Production Management, Vol. 21 No.1/2, pp.126-147.

Vickery, S., Calantone, R. and Droge, C. (1999), "Supply chain flexibility: an empirical study”, The Journal of Supply Chain Management, Vol.35 No.3, pp.16-24.

Vokurka, R.J. and O'Leary-Kelly, S.W. (2000), “A review of empirical research on manufacturing flexibility", Journal of Operations Management, Vol.18 No.4, pp.485501.

Voss, C., Tsikriktsis, N. and Frohlich, M. (2002), "Case research in Operations Management", International Journal of Operations and Production Management, Vol.22 No.2, pp.195-219.

Yin, R. (1984), Case Study Research, Sage Publications, Beverly Hills, CA.

Zeng, A.Z. (2000), “A synthetic study of sourcing strategies”, Industrial Management \& Data Systems, Vol.100 No.5, pp.219-226. 


\section{Appendix}

\section{Interview protocol}

Q1: How do you define supply flexibility?

Q2: How important is supply flexibility for you firm, compared to other purchasing performance dimensions (cost, quality, reliability)?

Q3: How do you measure supply flexibility?

Q4: Please describe the following processes: purchasing planning, purchasing, delivery, supply base management.

Q5: How often is production schedule revised? Is there a "frozen schedule" policy for deliveries?

For the following questions, please consider the purchased item that requires more supply flexibility:

Q6: How many suppliers deliver this product? Where are they located? Do these suppliers have other important customers for this product?

Q7: Why is this material critical with respect to supply flexibility?

Q8: Which factors are important to increase supply flexibility?

Q9: How many units are purchased each year?

Q10: How many different configurations / specifications are produced?

Q11: How long is the final product life cycle?

Q12: How much represents the supplier-specific investment for this product (in terms of specific assets, time and efforts dedicated to nurture the relationship, etc)? 